\title{
Spatial contribution of one-day precipitations variability to rainy days and rainfall amounts in Iran
}

\author{
H. Nazaripour • M. R. Mansouri Daneshvar
}

Received: 25 February 2014/Revised: 21 April 2014 / Accepted: 10 May 2014/Published online: 4 June 2014

(C) Islamic Azad University (IAU) 2014

\begin{abstract}
Rainfalls with short persistency are the tangible characteristics of arid and semiarid regions such as Iran. Iran is an arid and semiarid region with dramatic tempo-spatial changes of rainfall. In this regard, the short persistency of rainfall is approximately observed from 1 to 7 days in whole parts, while the greater ones are only separated in eastern parts of Iran. According to the results, the rainfall persistency is ranged from 1 to 45 days, but the maximum amount and rainy days are generated by rainfalls with short persistency. So, the rainfall events with long persistency are considered as an extreme event with extreme variability. One-day precipitations generate the maximum rainy days and rainfall amounts, especially in eastern parts of Iran. Decrease in the one-day precipitations contribution to eastern parts may indicate to decrease in regional precipitation. However, decrease in contribution in western parts may indicate to increased amounts of rainfall at other persistency rates. Our results revealed that the contribution of the one-day precipitation to general rainfall has reductive trends in almost $17.5 \%$ of the whole Iran. The most integrated and significant reductive trend of one-day precipitation contribution to rainfall spreads northeastern and eastern parts of Iran. However, in the western parts of Iran, decreasing one-day precipitation contribution to rainy days affects to increase in the diurnal
\end{abstract}

H. Nazaripour

Department of Environment, Institute of Science and High

Technology and Environmental Sciences, Graduate University

of Advanced Technology, Kerman, Iran

M. R. Mansouri Daneshvar $(\bowtie)$

Department of Geography, Mashhad Branch, Islamic Azad

University, Mashhad, Iran

e-mail: mrm_daneshvar2012@yahoo.com rainfall. The mentioned variability can be considered as the climate change signals in respect of one-day precipitation.

Keywords One-day precipitations $\cdot$ Persistency $\cdot$ Rainfall amounts - Spatial contribution · Trend analysis

\section{Introduction}

Mean annual precipitation of Iran in more than half of the surface area is less than $200 \mathrm{~mm}$, and some parts get less than $50 \mathrm{~mm}$ annually. On this basis, Iran is located through an arid and semiarid region. The topography is also associated with much of the spatial variation of annual precipitation. The annual extremes are located in northern Iran on the southwestern coast of the Caspian Sea, in the northwest and west on the western and southern slopes of the Zagros Mountains. The interior parts of the country receive much less precipitation (Alijani et al. 2008). In the recent decades, spatial and temporal precipitation in Iran has undergone several changes and approximately a half of the country expanse has been prone to them. In each part of Iran, the rainfall duration generates a portion of rainy days and rainfall amounts. Different patterns of rainfall generation such as topographic roughness, latitude and proximity to humidity in different parts of Iran causes to spatialtemporal changes in rainfall behaviors such as magnitude, persistency and so on. The spatial distribution for annual precipitation showed downward trend in northwestern and southeastern parts of Iran, whereas western, central and northeastern parts exhibited upward trend, though not statistically significant in most regions (Raziei et al. 2014). Theoretically, the contribution of precipitation trend is significantly related to rainy days and rainfall amounts. Trend analysis of rainfall data is essential for social and 
economic planning to measure the effects of climate change (Ghosh et al. 2009). A nonparametric test was taken into consideration over the parametric one since it can avoid the problem aroused by data skewness (Smith 2000). Mann (1945) presented a nonparametric test for randomness against time, which constitutes a particular application of Kendall's test for correlation commonly known as the Mann-Kendall or the Kendall $\tau$-test (Kendall, 1962). The Kendall's $\tau$-test is one of the nonparametric trend tests that have been frequently used in the literature. Recently, the Kendall's $\tau$-test has been described in widespread climatic studies by Longobardi and Villani (2009), Jain and Kumar (2012) and Kassile (2013). On this basis, the spatial distribution and temporal trend of precipitation have been widely studied in some regions such as Mediterranean areas (Rodrigo and Trigo 2007; Martínez et al. 2007; Longobardi and Villani 2009; Beguería et al. 2009; Mourato et al. 2010, López-Moreno et al. 2010), in Middle East (Türkeş et al. 2009; Almazroui et al. 2012), India (Guhathakurta and Rajeevan 2008; Jain and Kumar 2012; Dimri and Dash 2012) and Africa (Cheung et al. 2008; Senapathi et al. 2010; Kassile 2013). In the present study, we aimed to understand the variability contribution to oneday precipitation persistency into rainy days and total rainfall amount in whole Iran, during the time period of March 21, 1961 to December 30, 2004. Thus, the variability in annual contributions had been evaluated. A change in the variability can be considered as an evidence of climate change in the rainfall persistence. In the present study, the climate change signal is derived from systematic rainfall trends based on one-day precipitations and temporal distribution of rainy days. Changing trend in rainfall distribution is a critical importance in explaining climate change (e.g., Türkeş et al. 2009; Dimri and Dash 2010; Almazroui et al. 2012). For this purpose, the trend analysis has been carried out by using nonparametric Mann-Kendall test. A nonparametric trend test was dedicated to the time series, where it is assumed that its one-day precipitations contribution to them is a linear function of time. This is a statistical method which is being used to study the spatial variation and temporal trends of climatic series.

\section{Materials and methods}

\section{Study area}

Iran with a total area of 1.648 million $\mathrm{km}^{2}$ lies between $45^{\circ}$ and $63^{\circ}$ Eastern longitude and $25^{\circ}-40^{\circ}$ Northern latitude at the south west of Middle East. Climatic features of Iran have mostly an arid and semi-arid character, which is clearly linked to variation in the quantity of precipitation in different parts of Iran (Mansouri Daneshvar et al. 2013).
The mean annual rainfall over Iran is about $240 \mathrm{~mm}$. Maximum of it is about $1,800 \mathrm{~mm}$ on the Caspian seashore and about $400 \mathrm{~mm}$ in the sloping region of Alborz and Zagros mountains. The ranges of rainfall decrease to less than $100 \mathrm{~mm}$ annually depending on the location in the central and eastern parts of Iran. Cause of high variability in annual rainfall in Iran can be synoptic systems and yearto-year variation in the different number of passing cyclones (Soltani et al. 2012). The spatial distribution of annual precipitation in Iran has downward trend in northwestern to southeastern parts. Therefore, the spatial patterns of precipitation reflect the role of orography and latitudinal extent between central southern arid and semiarid regions and northern and western mountainous zones (Raziei et al. 2014).

\section{Data preparation}

To assess the contribution of one-day precipitations to rainy days and rainfall amounts, we used daily rainfall observations over the 1,437 hyetograph stations in Iran (Fig. 1). Diurnal observations of the mentioned stations were interpolated on a systematic reference grid $\left(15 \times 15 \mathrm{~km}^{2}\right)$ over the Iran, during the time period of March 21, 1961 to December 30, 2004. These diurnal time series of rainfall (15,991 day) were spatially analyzed according to an interpolation method in GIS. Calculation of rainfall durations in Iran and characterization of its behavior was achieved from geostatistical interpolation method of Kriging. Then, it was repeated for all temporal designated data. In this manner, rainfall time series of stations were converted to rainfall time series of nodes. According to ANOVA test and Q-Q plot, a trend analysis is performed

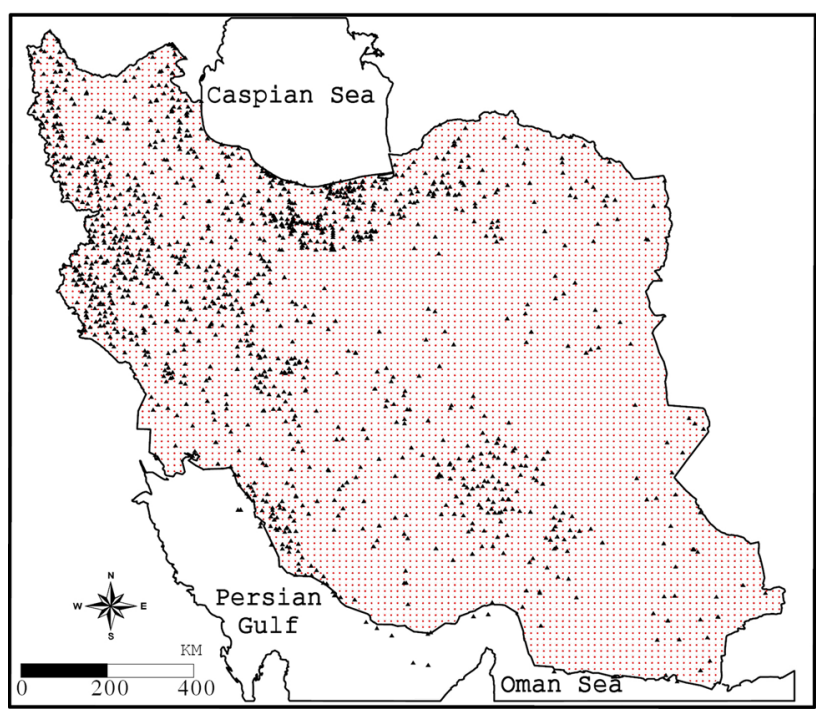

Fig. 1 Geographical distribution of 1,437 hyetograph stations and corresponding cells in Iran 
for these new series. The results confirmed the reliability of data entry and data analysis.

Data analysis

Rainfall duration in every of the 7,187 grid points was computed for consecutive rainy days with precipitation amount equal or more than $0.5 \mathrm{~mm}$. The threshold of $0.5 \mathrm{~mm}$ was decided based on the empirical characteristics and geostatistical modification for data interpolation. In previous same work, Senapathi et al. (2010) have taken the mentioned threshold of $0.85 \mathrm{~mm}$ or more to define rainy day. Then, contribution of lag-0 precipitation (1-day duration) was assessed both for the number of rainy days and for total rainfall amount. We first calculate the percentage of rainy days frequency and rainfall amounts, which are generated by one-day duration through each cell in reference grid $(1-7,187)$. For this purpose, first we assume the frequency of rainy days in every cells that generated by one-day precipitation, and then, we assume the frequency of rainy days in the same cells that generated by other durations, which commence from 2 to 45 days, in order to calculate the percentage of one-day precipitation contribution to rainy days. According to data analysis, it has been revealed that the short persistency and long persistency of rainfall duration are 1 and 45 days in whole Iran. Therefore, we assumed the rainfall amounts which generated by one-day precipitation, and then, total rainfall that generated by other duration to calculate the percentage of one-day precipitation in total rainfall amounts. Based on the calculation, the maximum rainy days and rainfall rate extended all over network calls are due to short-persistency precipitations such as one-day precipitation. In this regard, the percentage of rainfall durations was generated for all the network cells in Iran (Fig. 2). With the aim of trend detection and cross verification, a nonparametric statistical procedure is applied to the rainfall time series. A nonparametric trend test was dedicated to the time series, where it is assumed that its one-day precipitations contribution to them is a linear function of time. Kendal's $\tau$-test first ranks all observations by date order, the difference between each consecutive value is calculated, and then, the sum of the signs of these differences is calculated as the Kendall sum ( $S$ statistic) given in the following Eq. 1 (Salas 1993):

$S=\sum_{j=k}^{n-1} \sum_{j=k+1}^{n} \operatorname{sgn}\left(x_{j}-x_{k}\right)$

where $n$ is the number of data cells $(7,187)$ and the value of $\operatorname{sgn}\left(x_{j}-x_{k}\right)$ is computed in the following Eq. 2:

$\operatorname{sgn}\left(x_{j}-x_{k}\right)=\left\{\begin{array}{lll}+1 & \text { if } & \left(x_{j}-x_{k}\right)>0 \\ 0 & \text { if } & \left(x_{j}-x_{k}\right)=0 \\ -1 & \text { if } & \left(x_{j}-x_{k}\right)<0\end{array}\right.$

This statistics represents the number of positive differences minus the number of negative differences for all the differences considered. For large samples $(N>10)$, the test is conducted using a normal distribution with the mean and the variance (Helsel and Hirsch 1992). Under the Kendall's $t$ test, a positive value of $S$ in Eq. 1 indicates an increasing trend, whereas a negative value indicates a decreasing trend (Kahya and Kalayci 2004). The null and alternative hypotheses under $S$ were H0: There was no trend in the annual amounts of rainfall and Ha: There was a trend in the annual amounts of rainfall. Based on these calculations, one-day precipitations occur predominantly in the central and southern parts of Iran. The variability in its share can be considered as evidence of climate changes in these
Fig. 2 The percentage of rainfall durations for all the network cells in Iran

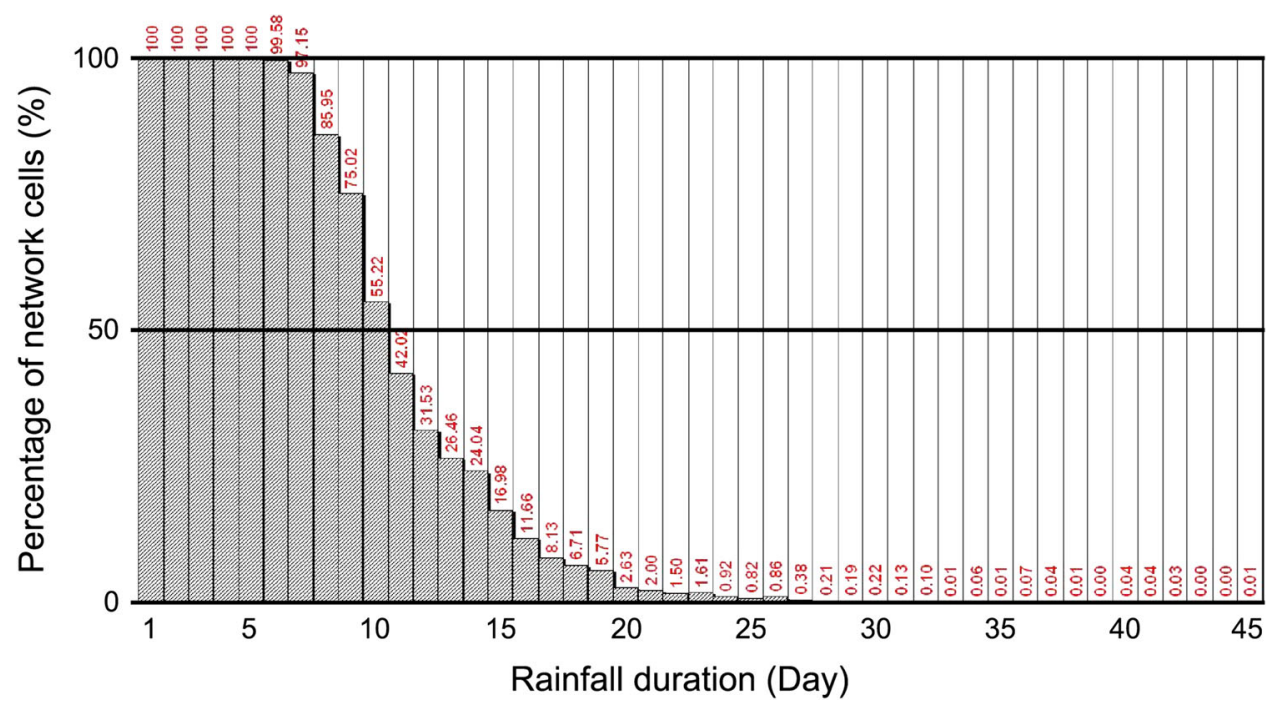


regions. At annual time series, one-day precipitations are separately contributed to rainy days and rainfall amounts in every cell. Trend analysis of a time series consists of the magnitude of trend and its statistical significance. In general, the magnitude of trend in a time series is determined either using regression analysis (parametric test) or using Sen's estimator method (nonparametric method). Sen's estimator has been widely used for determining the magnitude of trend in hydrometeorological time series (Lettenmaier et al. 1994; Yue and Hashino 2003; Partal and Kahya 2006). In this method, the slopes (Ti) of all data pairs are first calculated by Eq. 3 :

$T_{i}=\frac{x_{j}-x_{k}}{j-k} \quad$ for $\quad i=1,2, \ldots, n$

where $x_{j}$ and $x_{k}$ are data values at time $j$ and $k(j>k)$, respectively. The median of these $n$ values of $T_{i}$ is Sen's estimator of slope which is calculated by Eq. 4 :

$\beta=\left\{\begin{array}{cc}T_{\frac{n+1}{2}} & n \text { is odd } \\ \frac{1}{2}\left(T_{\frac{n}{2}}+T_{\frac{n+2}{2}}\right) & n \text { is even }\end{array}\right.$

A positive value of $\beta$ indicates an upward (increasing) trend, and a negative value indicates a downward (decreasing) trend in the time series. The $p$ value used in the Mann-Kendall test was in the $5 \%$ level of significance. All tests were carried out through implementing a M-File that was written in MATLAB software.

\section{Results and discussion}

Temporal distribution of rainfall may take long from 1 up to 45 days with extreme spatial changes in Iran. These changes become more severe when its persistency increases. Table 1 shows the spatial contribution of 1 - to

Table 1 Spatial contribution of 1- to 10-day durations of precipitation to rainy days and rainfall amounts in Iran

\begin{tabular}{lll}
\hline $\begin{array}{l}\text { Duration } \\
\text { (day) }\end{array}$ & $\begin{array}{l}\text { Contribution to rainy } \\
\text { days (percentage) }\end{array}$ & $\begin{array}{l}\text { Contribution to rainfall } \\
\text { amounts (percentage) }\end{array}$ \\
\hline 1 & 52.39 & 19.87 \\
2 & 25.55 & 25.01 \\
3 & 11.56 & 19.34 \\
4 & 5.31 & 12.82 \\
5 & 2.36 & 8.19 \\
6 & 1.36 & 5.27 \\
7 & 0.70 & 3.17 \\
8 & 0.39 & 2.17 \\
9 & 0.23 & 1.52 \\
10 & 0.12 & 0.77 \\
\hline
\end{tabular}

10-day durations of rainfall to rainy days and rainfall amounts in Iran. Rainfall duration contribution to rainy days and rainfall amounts also decreases strongly as the length of persistency increases. So that the maximum rate of rainy days is generated by short-persistency rates. Therefore, long-persistency precipitations in Iran have undergone severe spatial and temporal changes and are considered among infrequent rainfall events. Most of rainy days and most of rainfall amount in great parts of Iran are developed based on one-day precipitations as the most important rainfall persistency. Therefore, any variation and change in contribution of one-day precipitations to rainy days and rainfall amounts should be analyzed in whole Iran.

One-day precipitations contribution to rainy days

Rainfall duration in some parts of Iran, which received low amounts (i.e., central and eastern parts of Iran), has short persistency. So, rainfall duration in some parts of Iran, which received high amounts (i.e., western and northern parts of Iran), has long persistency. The spatial contribution of one-day precipitations to rainy days in eastern parts of Iran is more significant than the western parts. The mountainous ranges of Zagros and Alborz, as well as coastal parts of Caspian Sea, are as the high precipitation areas in Iran. However, these regions do not have any one-day precipitations contribution to rainy days. In other words, in these regions, rainfall durations take for longer than 1 day, and therefore, contribution of the oneday precipitations to rainy days is in minimum. Nevertheless, the most duration of rainy days in central Iran, southeastern and eastern parts is typically one day (Fig. 3a). Therefore, any variation and change in frequency of the regional one-day precipitations could to be taken into account. According to rainfall time series, it has been denoted that decrease in the regional one-day precipitations does not correspond to increase in long rainy days. Therefore, the attribution of regional one-day precipitation decrease into decreasing of rainy days and rainfall amounts is the evidence of climatic changes. Diversely, in western parts of Iran, decrease in the oneday precipitations contribution to rainy days may involve increase in contribution of other persistency of it. Otherwise, decrease in one-day precipitations contribution to rainy days in western parts can be considered as decrease in regional rainy days.

One-day precipitations contribution to general rainfall

The contribution of the one-day precipitations to the rainfall variability in Iran is not maximum and has various spatial patterns. Its contribution to eastern rainfalls (i.e., 

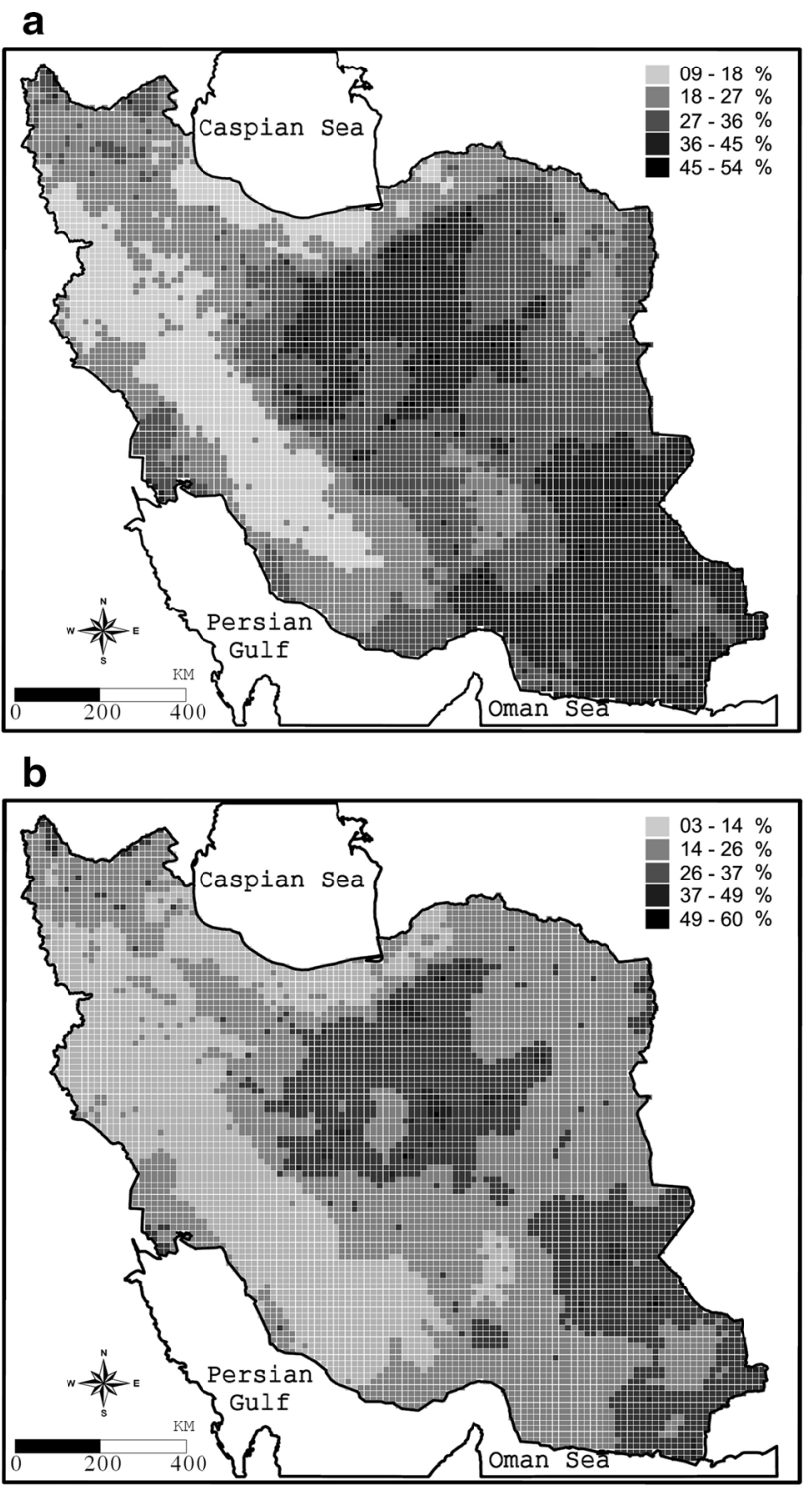

Fig. 3 a One-day precipitations contribution to rainy days, and b one-day precipitation contribution to rainfall amounts

central Iran, southeastern and eastern parts) has been excessive. Diversely, the one-day precipitations in western parts, especially in regions extended along the Zagros and coastal areas of Caspian Sea, minimally contribute to general precipitation. Therefore, as most of eastern rainy days and rainfall are affected by the one-day precipitations, any variation or change could be analyzed (Fig. 3b). Despite the fact that the one-day precipitations make up most of the rainy days in the western parts, most of the rainfalls are cumulated due to the more durations. So, decrease in the one-day precipitations contribution to eastern parts may indicate to decrease regional precipitation. However, decrease in contribution in western parts may indicate to increased amounts of rainfall at other
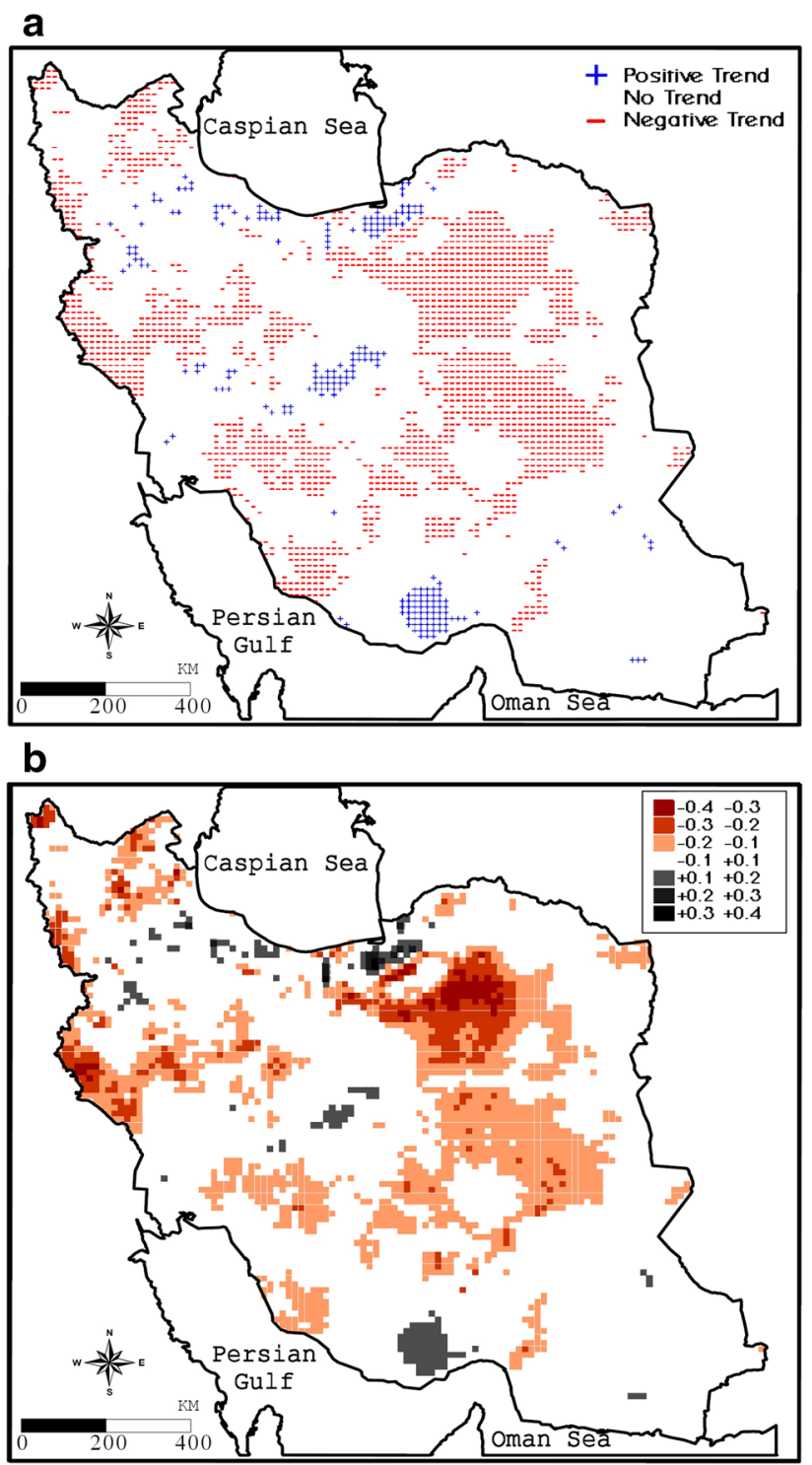

Fig. 4 a Variation in one-day precipitation contribution to rainy days and $\mathbf{b}$ slope variation in one-day precipitation contribution to rainy days $(p=0.05)$

persistency rates. Otherwise, decrease in the one-day precipitations contribution to western rainfall may be considered as climate change with respect to precipitation.

Trend analysis of one-day precipitation variability into rainy days

Trend analysis of the one-day precipitation contribution to rainy days shows that it is on the decline in almost $27 \%$ of whole Iran, especially in eastern parts. Furthermore, in western, northwestern and southwestern parts, the contribution of the one-day precipitation to rainy days also has a declining trend. In contrast, only $3 \%$ of the whole extents of Iran have an increasing trend. One-day precipitation 
contribution to rainy days has a gradient, the trend of which varying between -0.4 and 0.4 . As the maximum rate of precipitation contribution to the rainy days in eastern parts (i.e., central Iran, southeastern and eastern parts of Iran) one can claim that the rainy days frequency in central Iran decreases severely. In general, due to lack of humidity sources and lack of considerable topographic barrier, slight rainfall and a few rainy days occur in these regions. Furthermore, the regional rainfall has mainly short persistency. Therefore, taking into consideration the decreasing trend of one-day precipitation frequency, the decrease in rainy days in these regions may be due to a change in climate of Iran. On the other hand, since the
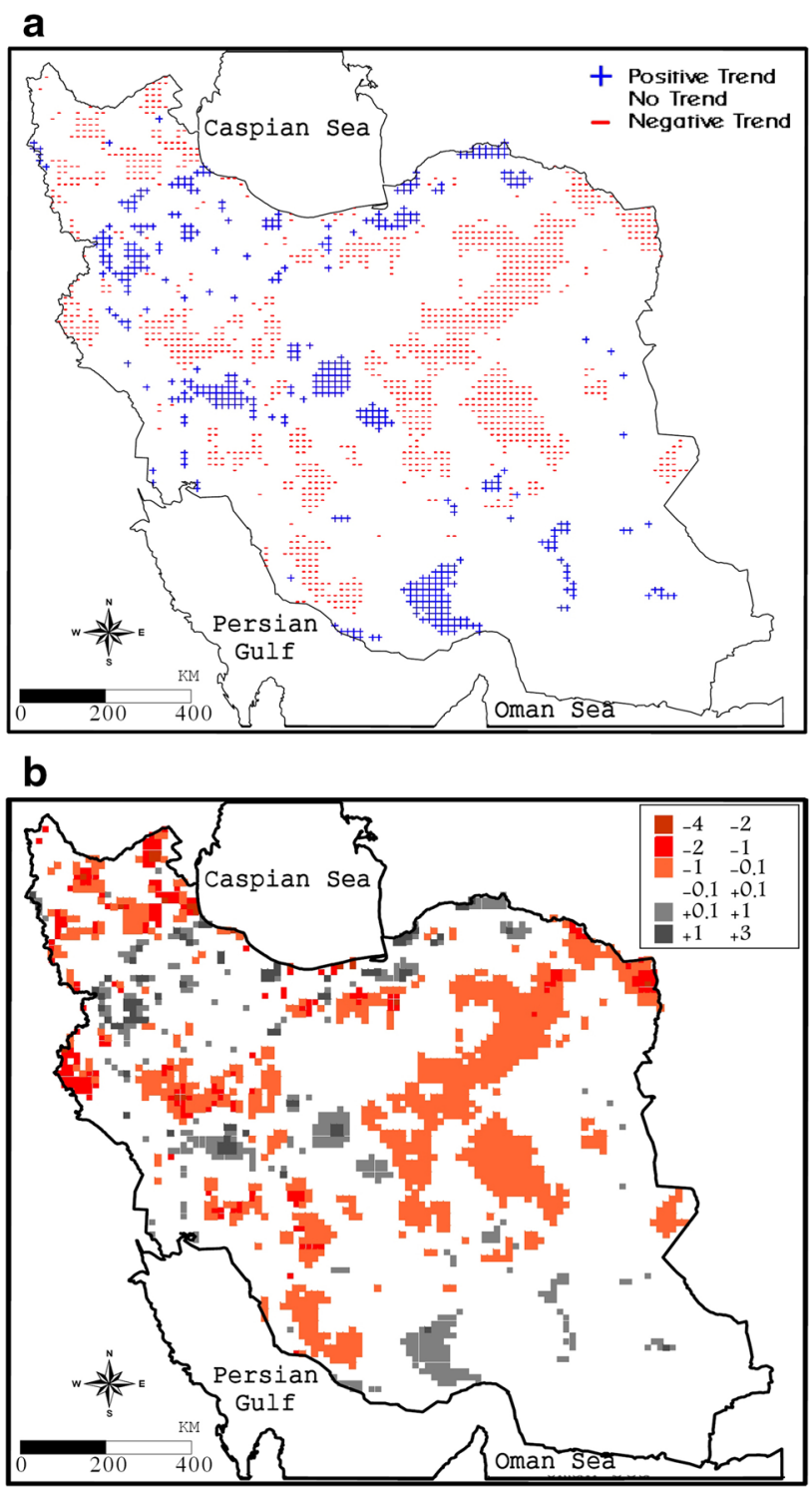

Fig. 5 a Variation in one-day precipitation contribution to rainfall amounts and $\mathbf{b}$ slope variation in one-day precipitation contribution to rainfall amounts $(p=0.05)$ maximum rainy days are also generated by one-day precipitation in whole Iran, one can claim with less certainty that frequency of rainy days has a declining trend in Iran and the gradient of which is more tangible at eastern low precipitated areas (Fig. 4a, b). In southeastern areas as well as eastern and northeastern parts of Iran, the one-day precipitation generates maximum rate of rainy days without any changes because two rainfall regimes are prevalent (i.e., wintry and summery regimes). The wintry hibernal regime in both the central and southeastern parts is developed from westerly currents and troughs. However, the summery one active in southeastern parts of Iran is under influence of monsoons of southeastern Asia (Gang low-pressure system). Therefore, multiplicity of precipitation regimes as well as proximity to humidifying sources may be considered as factors causing rainy days in southeastern parts with no decrease.

Trend analysis of one-day precipitation contribution to general rainfall

Contribution of the one-day precipitation to general rainfall has reductive and accretive trends in almost 17.5 and $6 \%$ of the whole Iran, respectively. The reductive trend of the one-day precipitation contribution to rainfall amounts is completely accordant with one-day precipitation contribution to rainy days. The most integrated and significant reductive trend of one-day precipitation contribution to rainfall spreads northeastern and eastern parts of Iran. In these ranges, contribution of the one-day precipitation to rainy days has a declining trend (Fig. 5a, b). Decrease in rainy days and rainfall amounts in eastern parts is most likely to be approved because to the weak role of other rainfall persistency rates. Reduction of rainy days and rainfall amounts in the eastern parts, especially at eastern parts of Iran, indicates change in Iranian climate.

\section{Conclusion}

The spatial and temporal changes of precipitation take long dependently from 1 day up to 45 days in Iran. Contribution of rainfall persistency to rainy days and rainfalls decreases severely over the contrary. These results are in agreement with findings of other researches for Iran, which have been provided by Modarres and Sarhadi (2009), Tabari and Hosseinzadeh Talaee (2011), Raziei et al. (2012). The maximum rainy days and rainfall amounts in Iran are attributed to short-persistency rainfall. The one-day precipitation contribution of rainfall amounts in eastern parts of Iran is more than the western parts. The most of rainy days developed in whole Iran. Contribution of the one-day 
precipitation to the eastern rainfall is much more than of the western one. Trend analysis of the one-day precipitation contribution to rainy days shows that it is on the decline in almost $27 \%$ of whole Iran, especially in eastern parts. Thus, the frequency of regional rainy days has reduced. Reduction of rainy days in these regions is considered as a climate change signal in respect of one-day precipitation because the eastern parts due to lack of humidity and spread of high altitude topographic barriers generally have low-cut precipitation and rainy days. Contribution of the one-day precipitation to general rainfall has reductive and accretive trends in almost 17.5 and $6 \%$ of the whole Iran, respectively. The reductive trend of the one-day precipitation contribution to rainfall amounts is completely accordant with one-day precipitation contribution to rainy days. The most integrated and significant reductive trend of one-day precipitation contribution to rainfall spreads northeastern and eastern parts of Iran. However, in the western parts of Iran, decreasing one-day precipitation contribution to rainy days affects to increase in the diurnal rainfall. It results in huge floods into streams over these regions, where it leads to erosion and soil losses as a climate change signal in western parts of Iran. Previous studies make it possible to assume aggregation of both the above-mentioned climate change signals (Nazaripour 2011).

Acknowledgments We are very grateful to Dr. Abolfazl Masoodian from Department of Geography at University of Isfahan in Iran and Dr. Mahmood Khosravi from Department of Geography at University of Sistan and Baluchestan in Iran for their superior advises. Thanks also to one anonymous reviewer for suggestions on data interpretations.

\section{References}

Alijani B, Brien JO, Yarnal B (2008) Spatial analysis of precipitation intensity and concentration in Iran. Theor Appl Climatol 94(1-2):107-124

Almazroui M, Islam MN, Athar H, Jones PD, Rahman MA (2012) Recent climate change in the Arabian Peninsula: annual rainfall and temperature analysis of Saudi Arabia for 1978-2009. Int J Climatol 32(6):953-966

Beguería S, Vicente-Serrano SM, López-Moreno JI, García-Ruiz JM (2009) Annual and seasonal mapping of peak intensity, magnitude and duration of extreme precipitation events across a climatic gradient, northeast Spain. Int J Climatol 29(12): 1759-1779

Cheung WH, Senay GB, Singh A (2008) Trends and spatial distribution of annual and seasonal rainfall in Ethiopia. Int $\mathrm{J}$ Climatol 28(13): 1723-1734

Dimri AP, Dash SK (2010) Winter temperature and precipitation trends in the Siachen Glacier. Curr Sci 98(12):1620-1625

Dimri AP, Dash SK (2012) Wintertime climatic trends in the western Himalayas. Clim Chang 111(3-4):775-800
Ghosh S, Luniya V, Gupta A (2009) Trend analysis of Indian summer monsoon rainfall at different spatial scales. Atmos Sci Lett 10:285-290

Guhathakurta P, Rajeevan M (2008) Trends in the rainfall pattern over India. Int J Climatol 28:1453-1469

Helsel DR, Hirsch RM (1992) Statistical methods in water resources. Elsevier, New York

Jain SK, Kumar V (2012) Trend analysis of rainfall and temperature data for India. Curr Sci 102(1):37-49

Kahya E, Kalayci S (2004) Trend analysis of stream flow in Turkey. J Hydrol 289:128-144

Kassile T (2013) Trend analysis of monthly rainfall data in central zone. J Math Stat 9(1):1-11

Kendall MG (1962) Rank correlation methods. Hafner Publishing Company, New York

Lettenmaier DP, Wood EF, Wallis JR (1994) Hydro-climatological trends in the continental United States, 1948-88. J Climate 7(4):586-607

Longobardi A, Villani P (2009) Trend analysis of annual and seasonal rainfall time-series in the Mediterranean area. Int $\mathrm{J}$ Climatol 30(10):1538-1546

López-Moreno JI, Vicente-Serrano SM, Angulo-Martínez M, Beguería S, Kenawy A (2010) Trends in daily precipitation on the northeastern Iberian Peninsula, 1955-2006. Int J Climatol 30(7):1026-1041

Mann HB (1945) Non-parametric test against trend. Econometrika 13:245-259

Mansouri Daneshvar MR, Bagherzadeh A, Khosravi M (2013) Assessment of drought hazard impact on wheat cultivation using standardized precipitation index in Iran. Arab $\mathrm{J}$ Geosci 6(11):4463-4473

Martínez MD, Lana X, Burgueño A, Serra C (2007) Spatial and temporal daily rainfall regime in Catalonia (NE Spain) derived from tour precipitation indices, years 1950-2000. Int J Climatol 27(1):123-138

Modarres R, Sarhadi A (2009). Rainfall trends analysis of Iran in the last half of the twentieth century. J Geophys Res 114(D03). doi:10.1029/2008JD010707

Mourato S, Moreira M, Corte-Real J (2010) Interannual variability of precipitation distribution patterns in Southern Portugal. Int $\mathbf{J}$ Climatol 30(12):1784-1794

Nazaripour H (2011) Synoptic analysis of Iranian rainfall persistency. $\mathrm{PhD}$ thesis. Sistan and Baluchestan University (In Persian)

Partal T, Kahya E (2006) Trend analysis in Turkish precipitation data. Hydrol Proc 20:2011-2026

Raziei T, Mofidi A, Santos JA, Bordi B (2012) Spatial patterns and regimes of daily precipitation in Iran in relation to large-scale atmospheric circulation. Int J Climatol 32(8):1226-1237

Raziei T, Daryabari J, Bordi I, Pereira LS (2014) Spatial patterns and temporal trends of precipitation in Iran. Theor Appl Climatol 115(3-4):531-540

Rodrigo FS, Trigo RM (2007) Trends in daily rainfall in the Iberian Peninsula from 1951 to 2002. Int J Climatol 27(4):513-529

Salas JD (1993). Analysis and modeling of hydrologic time-series. In: DR Maidment (ed), Handbook of hydrology. McGraw-Hill, New York, pp 19.1-19.72

Senapathi D, Underwood F, Black E, Nicoll MAC, Norris K (2010) Evidence for long-term regional changes in precipitation on the East Coast Mountains in Mauritius. Int $\mathrm{J}$ Climatol 30(8):1164-1177

Smith LC (2000) Trends in Russian Arctic river-ice formation and breakup, 1917 to 1994. Phys Geogr 20(1):46-56

Soltani S, Saboohi R, Yaghmaei L (2012) Rainfall and rainy days trend in Iran. Clim Chang 110(1-2):187-213 
Tabari H, Hosseinzadeh Talaee P (2011) Temporal variability of precipitation over Iran: 1966-2005. J Hydrol 396(3-4):313-320

Türkeş M, Koç T, Sariş F (2009) Spatiotemporal variability of precipitation total series over Turkey. Int $\mathrm{J}$ Climatol 29(8):1056-1074
Yue S, Hashino M (2003) Temperature trends in Japan: 1900-1996. Theor Appl Climatol 75(1-2):15-27 